\title{
Juvenile corals underpin coral reef carbonate production after disturbance
}

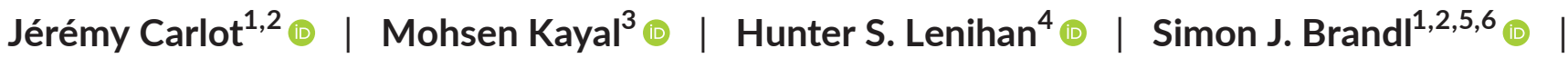 \\ Jordan M. Casey ${ }^{1,2,6} \odot$ | Mehdi Adjeroud ${ }^{1,2,7} \odot$ | Ulisse Cardini ${ }^{8,9}{ }_{\odot}$ | \\ Alexandre Merciere $^{10}$ | Benoit Espiau ${ }^{10}$ | Diego R. Barneche ${ }^{11}$ (ㅇ) | Alessio Rovere ${ }^{12}$ (ㅇ | \\ Laetitia Hédouin $^{2,10}$ | Valeriano Parravicini ${ }^{1,2}$ ( \\ ${ }^{1}$ PSL Université Paris, USR 3278 CRIOBE - EPHE-UPVD-CNRS, Perpignan, France \\ ${ }^{2}$ Laboratoire d'Excellence "CORAIL", Paris, France \\ ${ }^{3}$ ENTROPIE, IRD, Université de la Réunion, CNRS, IFREMER, Université de la Nouvelle-Calédonie, Nouméa, New Caledonia \\ ${ }^{4}$ Bren School of Environmental Science and Management, University of California, Santa Barbara, CA, USA \\ ${ }^{5}$ CESAB - FRB, Montpellier, France \\ ${ }^{6}$ Department of Marine Science, University of Texas at Austin, Marine Science Institute, Port Aransas, TX, USA \\ ${ }^{7}$ ENTROPIE, IRD, Université de la Réunion, CNRS, Perpignan, France \\ ${ }^{8}$ Integrative Marine Ecology Department, Stazione Zoologica Anton Dohrn, National Institute of Marine Biology, Ecology and Biotechnology, Napoli, Italy \\ ${ }^{9}$ Marine Research Institute, University of Klaipeda, Klaipeda, Lithuania \\ ${ }^{10}$ PSL Université - EPHE-UPVD-CNRS, USR 3278 CRIOBE, Papetoai, French Polynesia \\ ${ }^{11}$ Australian Institute of Marine Science, Crawley, WA, Australia \\ ${ }^{12}$ Centre for Marine Environmental Sciences (MARUM, Bremen, Germany
}

\section{Correspondence}

Jérémy Carlot, PSL Université Paris, USR 3278 CRIOBE - EPHE-UPVD-CNRS,

Perpignan, France.

Email: jay.crlt02@gmail.com

\section{Funding Information}

This research was supported by the BNP Foundation (Reef Services Project), the French Polynesian government (RisqueRecif Project), the Fondation de France (Acid Reefs project), the Fondation pour la Recherche et Biodiversité and Ministère de la Transition Ecologique et Solidaire (Acid Reefs 2 project). This research is also product of the SCOREREEF group funded by the Centre de Synthèse et d'Analyse sur la Biodiversité (CESAB) of the Foundation pour la Recherche sur la Biodiversité (FRB) and the Agence Nationale de la Biodiversité (AFB). VP was supported by the Institut Universitaire de France (IUF), JMC was supported by a Make Our Planet Great Again Postdoctoral Grant (mopgapdf-0000000144).

\begin{abstract}
Sea-level rise is predicted to cause major damage to tropical coastlines. While coral reefs can act as natural barriers for ocean waves, their protection hinges on the ability of scleractinian corals to produce enough calcium carbonate $\left(\mathrm{CaCO}_{3}\right)$ to keep up with rising sea levels. As a consequence of intensifying disturbances, coral communities are changing rapidly, potentially reducing community-level $\mathrm{CaCO}_{3}$ production. By combining colony-level physiology and long-term monitoring data, we show that reefs recovering from major disturbances can produce $40 \%$ more $\mathrm{CaCO}_{3}$ than currently estimated due to the disproportionate contribution of juvenile corals. However, the buffering effect of highly productive juvenile corals is compromised by recruitment failures, which have been more frequently observed after large-scale, repeated bleaching events. While the size structure of corals can bolster a critical ecological function on reefs, climate change impacts on recruitment may undermine this buffering effect, thus further compromising the persistence of reefs and their provision of important ecosystem services.
\end{abstract}

KEYWORDS

$\mathrm{CaCO}_{3}$ production, calcification rates, coral assemblages, coral juveniles, linear extension, reef productivity, time series 


\section{1 | INTRODUCTION}

The Intergovernmental Panel on Climate Change (IPCC) predicts a climate-driven sea-level rise of $0.43 \mathrm{~m}-0.84 \mathrm{~m}$ by 2100 (Oppenheimer et al., 2019), thus increasing the risk of coastal flooding, especially during tropical storms (Ellison et al., 2019; Nunn et al., 2017; Tebaldi et al., 2012). Sea-level rise will be amplified in the tropics, where vulnerable ecosystems such as mangroves and coral reefs act as natural barriers to protect more than 500 million people from oceanic waves (Hoegh-Guldberg et al., 2007). For coasts protected by coral reefs, their future exposure to oceanic waves will largely depend on the ability of scleractinian corals to produce enough calcium carbonate $\left(\mathrm{CaCO}_{3}\right)$ for reefs to grow vertically at a rate equivalent to sea-level rise. However, reefs are increasingly threatened by both climate change and local anthropogenic disturbances (Darling et al., 2019; Hughes et al., 2017). Climate-induced coral bleaching is expected to become an annual phenomenon for most coral reefs within the next 20 years (van Hooidonk et al., 2016), inducing a state of constant disturbance that decreases the likelihood of recovery. Whether reefs and their services will persist is presently unknown and requires the assessment of reef $\mathrm{CaCO}_{3}$ production across disturbance-recovery cycles (Harris et al., 2018; Perry, Alvarez-Filip, et al., 2018).

The quantification of $\mathrm{CaCO}_{3}$ production $\left(\mathrm{kg} \mathrm{m}^{-2}\right.$ year $\left.{ }^{-1}\right)$ for reefscapes is traditionally based on species-specific linear extension rates of corals combined with the proportional substratum cover of the species. In most cases, this is applied to each colony regardless of their size (Perry et al., 2018). Depending on the coral growth form, this scaling process relies on the assumption that species-specific $\mathrm{CaCO}_{3}$ production rates are constant throughout coral ontogeny. However, this may not always be the case as $\mathrm{CaCO}_{3}$ production rates may be either allometric or isometric (Figure 1). In the case of isometry, $\mathrm{CaCO}_{3}$ production rate scales linearly with colony size; conversely, in the case of allometry, $\mathrm{CaCO}_{3}$ production rate either accelerates or decelerates as colonies grow. While it is often assumed that the coral colony-level production of $\mathrm{CaCO}_{3}$ is isometric, recent work suggests that coral growth (expressed as an increase in planar area) is allometric, either because large colonies experience higher rates of partial mortality (Madin et al., 2020) and/or because coral colonies allocate less energy to $\mathrm{CaCO}_{3}$ production in favor of reproduction once they reach a certain size (Kayal et al., 2015). Whether coral growth is indeed isometric or allometric remains poorly resolved, but may significantly influence our communitywide estimates of $\mathrm{CaCO}_{3}$ production (Figure 1). If corals grow allometrically, assuming isometry may lead to an underestimation of the production by small colonies and significantly obscure overarching estimates of $\mathrm{CaCO}_{3}$ production patterns across reefscapes.

Recent climate-driven disturbances, especially catastrophic coral-bleaching events and major storms, can substantially alter the size distribution of coral assemblages (Dietzel et al., 2020). Large perturbations often remove a substantial proportion of large coral colonies and leave the remaining assemblage dominated by small corals (Alvarado et al., 2016; Holbrook et al., 2018). In these situations, isometric approaches may lead to a severe underestimation of overall $\mathrm{CaCO}_{3}$ production, thus inhibiting our ability to infer a reef's ability to regain coral cover. Yet, the loss of large corals may also significantly reduce overall fecundity, leading to reduced coral recruitment and thus inhibiting coral recovery (Hughes \& Tanner, 2000). This negative feedback loop can diminish the overall productivity of reefs over time (Hughes et al., 2019). According to recent estimates, most coral reefs have a net production of $\mathrm{CaCO}_{3}$ close to zero (Perry, Alvarez-Filip, et al., 2018; Woodroffe \& Webster, 2014). Therefore, even slight differences in $\mathrm{CaCO}_{3}$ production may have major implications for the capacity of reefs to survive despite sea-level rise.

Here, we estimate $\mathrm{CaCO}_{3}$ production rates of three prominent coral genera over a range of colony sizes and test whether $\mathrm{CaCO}_{3}$

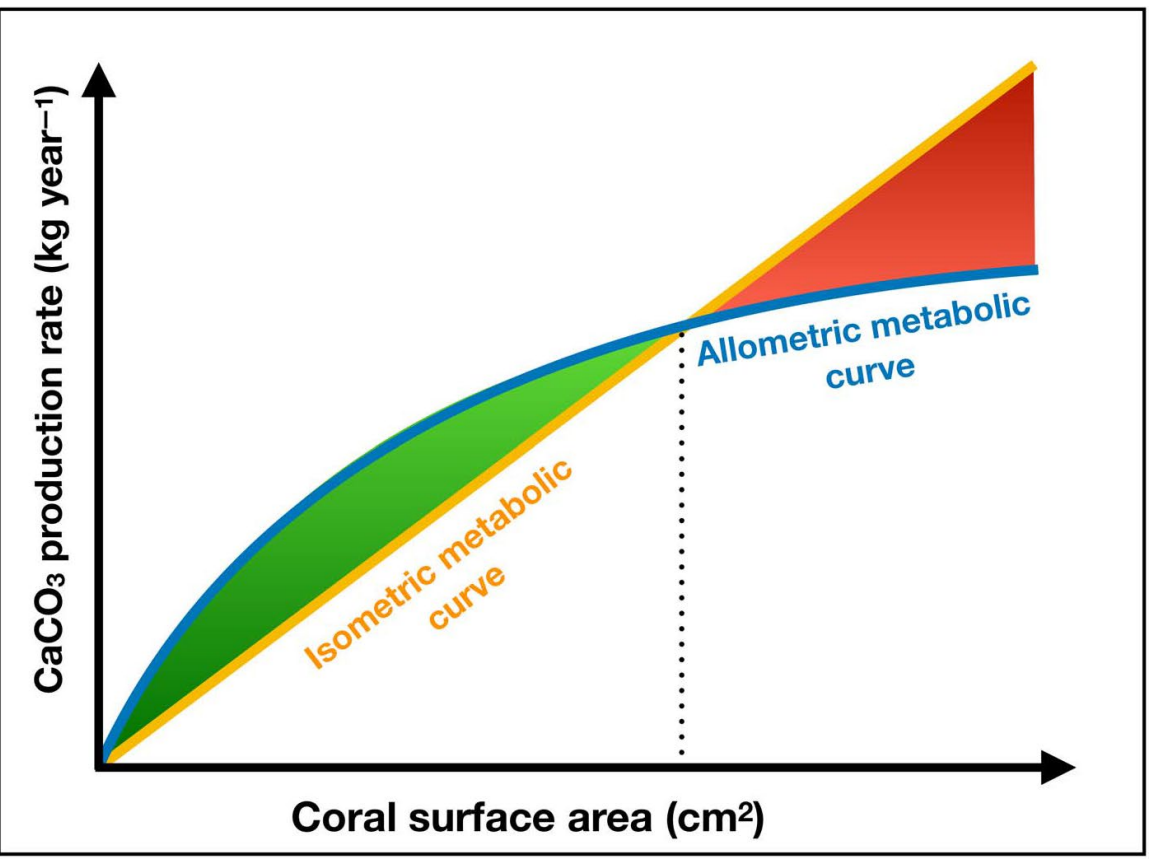

FIGURE 1 Conceptual diagram describing isometric versus allometric $\mathrm{CaCO}_{3}$ production curves. Size-dependent metabolic production characterized by (a) a linearly increasing model with coral surface area (isometric metabolic curve in orange; equation $y=x+0$ ), and (b) a logarithmic asymptote (allometric metabolic curve in blue; equation $\left.y=x^{\beta}+0\right)$. The dashed line indicates the size at which the two curves cross (i.e., this threshold point depends on both the intercepts and the allometric scaling slopes). Compared to the allometric model, the isometric model may underestimate $\mathrm{CaCO}_{3}$ production below this threshold and overestimate $\mathrm{CaCO}_{3}$ production at lager coral sizes [Colour figure can be viewed at wileyonlinelibrary. com] 
production follows an allometric or isometric growth pattern. We then use an empirical time-series dataset from French Polynesia that reports the size of individual coral colonies across 10 years of disturbance-recovery cycle to examine whether the conventional isometric approach leads to an incorrect estimation of communitylevel $\mathrm{CaCO}_{3}$ production. Finally, we evaluate the outcome of largescale disturbances, such as a major bleaching event, simulating the effect of recruitment loss on $\mathrm{CaCO}_{3}$ production over 5 years.

\section{2 | METHODS}

\section{1 $\mathrm{CaCO}_{3}$ production using in situ alizarin red-S staining}

In June 2018, we used the approach described by Dustan (1975) to stain 175 coral colonies of Acropora hyacinthus ( $n=50$ ), Pocillopora verrucosa $(n=75)$, and Porites lutea $(n=50)$ in situ at a depth of 10 $15 \mathrm{~m}$ on the outer reef slopes around the island of Mo'orea (French Polynesia, Figure S1). Before staining, we measured the length, width, and height of each coral colony. We stained colonies with a surface area ranging from $140 \mathrm{~cm}^{2}$ (i.e., $5 \mathrm{~cm}$ diameter) to $3850 \mathrm{~cm}^{2}$ (i.e., $\sim 80 \mathrm{~cm}$ diameter), which broadly matches the range of coral colony sizes observed in Mo'orea (Kayal et al., 2018; coral colonies observed in situ ranged from $<1 \mathrm{~cm}^{2}$ to $\sim 5000 \mathrm{~cm}^{2}$ ). We enclosed each coral in a 5, 10, or $20 \mathrm{~L}$ transparent plastic bag, filled with $10 \mathrm{mg} / \mathrm{L}$ of alizarin red-S, for 72 hours. All colonies were tagged and mapped for future retrieval. To minimize the confounding effects of competition on growth, we chose colonies that were not in direct contact with other corals. In December 2018, $74 \%$ of colonies ( $n=130$ ) were recovered and three fragments were collected from each coral for growth measurements. We reasoned that a period of 6 months was representative of the mean annual growth rate, since it covered the average temperatures typical for the cooler $\left(26^{\circ} \mathrm{C}\right)$ and warmer $\left(29^{\circ} \mathrm{C}\right.$ ) seasons in Mo'orea (cf. Smith et al., 2007). Samples were dried for 48 hours and placed into transparent epoxy for 24 hours before slicing three $0.7 \mathrm{~mm}$ thick slices from each colony using a diamond-tipped saw, perpendicular to the major axis of growth. We took high-resolution photos of each colony slice using fluorescence, and calculated linear extension as the average of three measurements (i.e., length, width, and height) per colony (Figure S2). We also measured the longest linear extension from the edge of the stain to the periphery of the skeleton to the nearest $0.1 \mathrm{~mm}$ using Image J software (Schneider et al., 2012). Finally, we calculated the $\mathrm{CaCO}_{3}$ production rate using the equation $C=(L E \times D) \times A C$, where $C$ represents the $\mathrm{CaCO}_{3}$ production rate $\left(\mathrm{g} \mathrm{cm}^{-2}\right.$ year $\left.^{-1}\right)$, LE represents the linear extension (cm/year), D represents the skeletal density, measured by the buoyed weight displacement method (respectively, 1.4, 1.5 , and $1.3 \mathrm{~g} / \mathrm{cm}^{3}$ for $A$. hyacinthus, $P$. verrucosa, and $P$. lutea), and AC represents the adjustment coefficient (between 0 and 1), depending on the growth form of the colony (Morgan \& Kench, 2012). We used an $\mathrm{AC}$ of $0.4,0.5$, and 1 for $A$. hyacinthus, $P$. verrucosa, and P. lutea, respectively.

\section{2 - $\mathrm{CaCO}_{3}$ production using alkalinity anomaly ex situ incubations}

To characterize $\mathrm{CaCO}_{3}$ production in smaller colonies, for which the Alizarin red-S approach was not feasible, we removed 96 coral colonies [A. hyacinthus $(n=25), P$. verrucosa $(n=25)$, and $P$. lutea $(n=46)]$ with surface areas of $35-1000 \mathrm{~cm}^{2}$ (i.e., $\sim 3-15 \mathrm{~cm}$ diameter) from the north shore of Mo'orea (depth $=12 \mathrm{~m}$ ) using a hammer and chisel. Before each collection, we recorded relevant environmental parameters (mean ambient seawater temperature, salinity, and photosynthetically active radiation). Upon return to the surface, we placed colonies in seawater tanks under the same environmental conditions for recovery and acclimation. Sponges, crustose coralline algae (CCA), macro-algae, epiphytes, and small crustaceans were carefully removed from the corals. We measured the length, width, and height of each colony, then tagged and kept the corals in the acclimation tank for 7 days. $73 \%$ of the colonies $(n=70)$ did not show any obvious adverse reactions to collected and handled, so we retained them for $\mathrm{CaCO}_{3}$ production measurements. Coral colonies were grouped into three different size classes $\left(<100 \mathrm{~cm}^{2}, 100-400 \mathrm{~cm}^{2}\right.$, and $400-$ $1000 \mathrm{~cm}^{2}$-see Section 2.3). Size selection for the incubation chambers was based on providing sufficient water volume for each coral colony, while ensuring traceability of changes in water chemistry (Kolb, 2018). Consequently, colonies were incubated in chambers of three different volumes $(0.5,1$, and $4 \mathrm{~L}$, respectively) to maintain a relatively constant incubation volume to colony size ratio. Four additional incubation chambers were used as blank controls. Each week, we assessed four controls and four corals of each size class. Water samples of $50 \mathrm{~mL}$ were collected from the incubation controls and each chamber after 3 hours of incubation for total alkalinity analysis. We made sure that coral colonies did not experience $\mathrm{O}_{2}$ reductions of more than $80 \%$ (Kolb, 2018), in which case observations were removed from the dataset. We defined net $\mathrm{CaCO}_{3}$ production by assuming a mole of $\mathrm{CaCO}_{3}$ is produced when the alkalinity measure $(\triangle \mathrm{AT})$ drops by two moles for a fixed time $(\Delta \mathrm{t})(\mathrm{S}$. $V$ Smith \& Key, 1975). By multiplying these parameters $(-\Delta A T / 2 . \Delta t)$ by seawater density $\left(\rho_{\text {sw }}\right)$, we defined the global $\mathrm{CaCO}_{3}$ production rate, which was then normalized with live coral surface area and converted to $\mathrm{g} \mathrm{cm}^{-2}$ year ${ }^{-1}$ based on the molar $\mathrm{CaCO}_{3}$ mass (Dickson et al., 2007).

\section{3 | Photogrammetry-based size-area relationships}

To examine the relationship between $\mathrm{CaCO}_{3}$ production and colony size, we used a 3D surface area to avoid underestimating coral $\mathrm{CaCO}_{3}$ production, as surface folding and branching increase the coral surface area. Following the coral incubation protocol, 100200 overlapping high-resolution photos were taken for each colony (Figure S3). The photos were used to construct 3D models using Agisoft PhotoScan (Agisoft LLC, 2016). We defined volume and live surface area from the final 3D model (i.e., outside area of the coral minus the base). We fitted a power-law regression between coral 
colony mean diameter (i.e., mean of the three dimensions defined for each colony) and coral live surface area $\left(R^{2}=0.97\right.$ ) (Kayal et al., 2015). This relationship was used to estimate the surface area of the coral colonies measured during the alizarin red-S staining, incubation experiments, and size distribution surveys.

\subsection{Bayesian $\mathrm{CaCO}_{3}$ production models}

To test whether $\mathrm{CaCO}_{3}$ production of the three coral genera followed an allometric or isometric pattern, we first verified that the $\mathrm{CaCO}_{3}$ production from in situ alizarin red-S staining and ex situ incubations was analogous. Alizarin red-S staining has the advantage of providing data from corals in situ (i.e., growing under normal environmental conditions). However, given the potential for toxicity in juvenile corals (Dustan, 1975), $\mathrm{CaCO}_{3}$ production of juveniles is better estimated with ex situ incubations. In our study, alizarin red-S staining and alkalinity anomaly incubation yielded similar results for $\mathrm{CaCO}_{3}$ production (Figure S4); therefore, we merged the datasets to estimate isometric and allometric relationships with Bayesian inference as follows:

$$
\begin{gathered}
C_{i} \sim N\left(\mu_{i}, \sigma^{2}\right), \text { Allometric model: } \mu_{i}=\alpha x_{i}^{\beta} \\
\text { Isometric model: } \mu_{i}=\alpha x_{i}+\beta
\end{gathered}
$$

where $\mathrm{C}_{\mathrm{i}}$ is the $\mathrm{CaCO}_{3}$ production rate ( $\mathrm{g} /$ year) and $\mathrm{x}_{\mathrm{i}}$ the live coral surface area $\left(\mathrm{cm}^{2}\right)$. We specified the same priors for both models ( Normal $(10,10)$ and $\beta \sim$ Normal $(0.5,0.5))$ with a weakly informative variance $\left(\sigma^{2} \sim\right.$ Student $\left.(3,0,450)\right)$. We fitted our models with 3000 iterations across four chains, and discarded the first 1500 warm-up iterations of each chain. We verified chain convergence with visual inspection and confirmed that Rhat (the potential scale-reduction factor) was less than 1.05. Using the model summary parameters, we then predicted both $\mathrm{CaCO}_{3}$ production and area-normalized $\mathrm{CaCO}_{3}$ production rates ( $\pm 95 \%$ Bayesian credible interval).

\subsection{Coral community $\mathrm{CaCO}_{3}$ production}

We used both isometric and allometric functions for quantifying community wide $\mathrm{CaCO}_{3}$ production to test whether the two approaches yielded different results when coral size distribution changes over time. Between 2005 and 2016, Mo'orea experienced an outbreak of the predatory sea star Acanthaster cf. solaris (20062009), followed by a cyclone (2010). The two disturbances reduced live coral cover from approximately 50\% in 2005 to $3 \%$ in 2010 (Carlot et al., 2020; Kayal et al., 2012). Following the disturbances, coral cover recovered to predisturbance levels by 2016 (Kayal et al., 2018; Figure 2). The change in coral cover was accompanied by considerable variations in coral size distributions. Large colonies were dominant in 2005 (Table S1) but were dramatically outnumbered by small recruits in 2011 (Adjeroud et al., 2018). We applied both $\mathrm{CaCO}_{3}$ production models (i.e., isometric versus allometric) at the community level by combining data from three studies that recorded temporal changes in size distributions of the three major reef-building corals around Mo'orea. The first study evaluated coral size distributions in 2005 (Adjeroud et al., 2015), the second study took place from 2008 to 2010 (Kayal et al., 2015), and the third study was conducted from 2011 to 2016 (Kayal et al., 2018) as part of the Mo'orea Coral Reef Long Term Ecological Research program (LTER; http://mcr.lternet.edu). All surveys were conducted at a

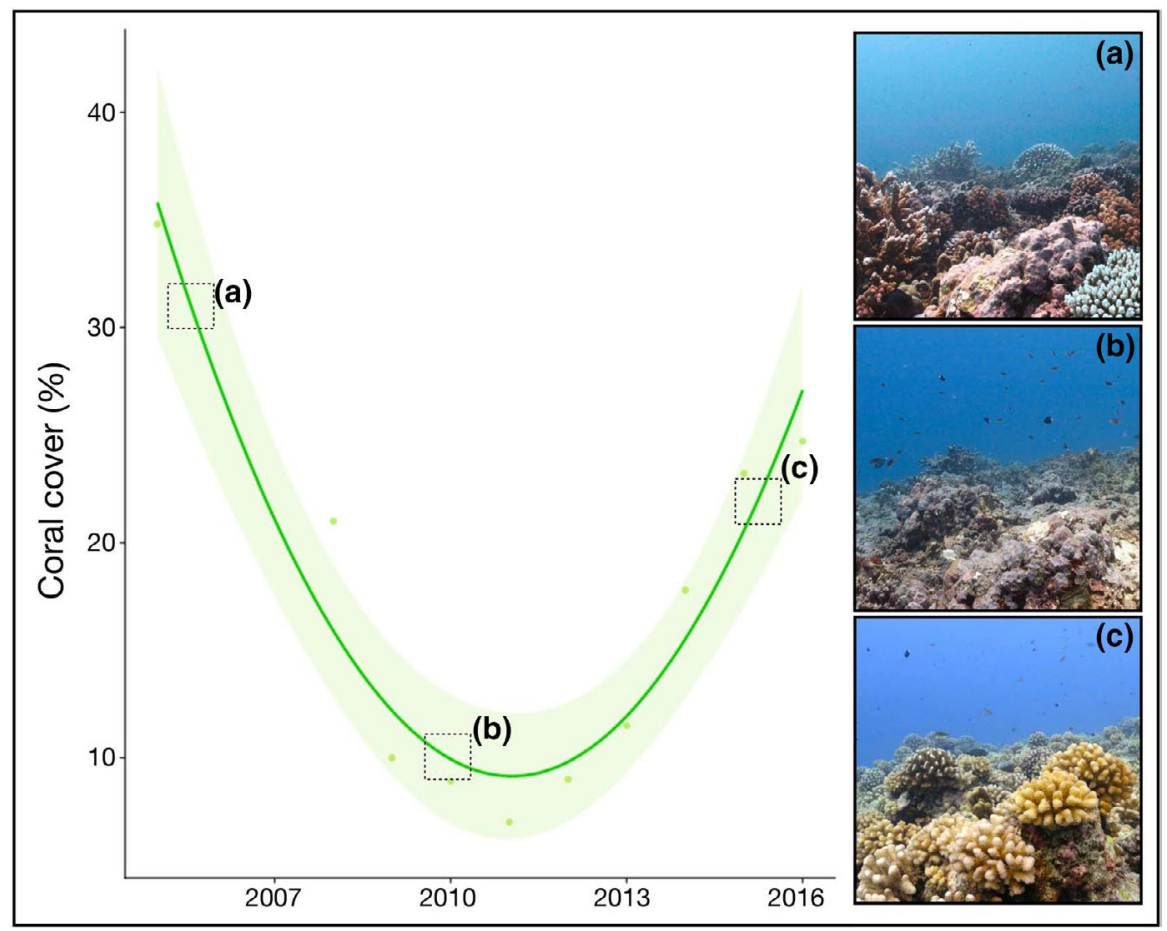

FIGURE 2 Average live coral cover in Mo'orea, French Polynesia, from 2005 to 2016. Perturbations included a predatory sea star (Acanthaster cf. solaris) outbreak from 2006 to 2009 and a cyclone in 2010. Photographs illustrate the reefscape in (a) 2006, (b) 2010, and (c) 2015 [Colour figure can be viewed at wileyonlinelibrary.com] 
minimum of three different sites around Mo'orea at a depth of approximately $12 \mathrm{~m}$.

Due to heterogeneity among datasets (i.e., differences in survey protocols, efforts, sites, and observers), we standardized the data by pooling all transects for a given year to obtain an island-scale coral size distribution for each taxon, from which we estimated population abundances matching the percent cover of the species at each site. To do so, we assumed that the planar shape of our three species is approximated by a circle when observed from above. We then calculated individual colony planar areas from visually determined length and width (i.e., ((length + width) $/ 4)^{2} \pi$ ). In some of the studies, coral size distribution was evaluated without recording the sampling effort (e.g., by recording the size of the 50 first colonies intercepted along a transect). Therefore, we evaluated coral density per $10 \mathrm{~m}^{2}$ substrate by randomly sampling individuals from our island-scale size distribution dataset until matching the percent cover of the species in each year. We repeated this process 100 times to obtain an average island-scale coral size distribution per taxon per year. We compared our coral size distribution estimates with empirical data collected in 2009 by Kayal et al. (2015) for the three coral species and found no significant difference (Figure S4). Annual changes in coral cover for the three coral genera were estimated as part of the "Service d'Observatoire CORAIL" monitoring (SO CORAIL monitoring; http://obser vatoire.criobe.pf). We then assigned $\mathrm{CaCO}_{3}$ production to each colony and summed them to yield total production per $10 \mathrm{~m}^{2}$ of reef.

\section{6 | Recruitment loss model}

To estimate how large-scale disturbance events may impact reef $\mathrm{CaCO}_{3}$ production, we used a multi-species, open-population, integral projection model (IPM) developed to characterize coral community dynamics around Mo'orea (Kayal et al., 2018). The IPM predicted recovery dynamics in the abundance, composition, and size distribution of coral assemblages (i.e., Acropora, Pocillopora, and Porites) after the 2006-2010 disturbances (Figure S6). For each population, the model is governed by the following:

$$
n \cdot(z \prime, t+1)=\int_{\text {Low }}^{U p} s(z) G\left(z, z^{\prime}\right) n(z, t) d z+R(\gamma, z \prime)
$$

where the distribution of individuals $n\left(z^{\prime}, t+1\right)$ of final size $z^{\prime}$ at time $t+1$ is predicted as a function of the distribution of the individuals $n$ $(z, t)$ of sizes $z$, bounded to the size-range interval [Low, Up], at time $t$. The functions $s, G$, and $R$ describe empirically estimated size (z)dependent survival and growth, and density $(\gamma)$-dependent recruitment, respectively.

We used the IPM to simulate the recovery of coral assemblages from 2010 to 2015 according to different recruitment scenarios. Specifically, we compared reef recovery under the observed recruitment rates (present-day scenario $R \times 1$ ) versus different scenarios of decline where recruitment was restricted to $75 \%, 50 \%$, and $25 \%$ of the observed values (scenarios $\mathrm{R} \times 0.75, \mathrm{R} \times 0.5$, and $\mathrm{R} \times 0.25$, respectively). The model was implemented with estimates of coral demographic parameters based on empirically measured coral survival, growth, and recruitment rates on the north shore of Mo'orea, where coral recruitment and recovery achieved maximum levels in 20102015 (Kayal et al., 2018). Finally, the allometric Bayesian model was applied to the distribution of the coral colonies' surface area predicted under the four recruitment scenarios (Figure S6) to estimate $\mathrm{CaCO}_{3}$ production rates (Figure 4). All statistics and predictive models were run using the brms and nlme packages (Bürkner, 2017a, 2017b; Pinheiro et al., 2013) in R version 3.5.3 (R Core Team, 2019).

\section{3 | RESULTS}

All three coral species exhibited an allometric linear extension pattern, with small coral colonies producing disproportionately larger amounts of $\mathrm{CaCO}_{3}$ per unit surface area than larger colonies (Figure 3). For example, a fivefold increase in colony surface area from 100 to $500 \mathrm{~cm}^{2}$ led to a $26 \%$ decline in linear extension for Acropora and Pocillopora and a 10\% decrease for Porites.

According to the isometric model, reef-scale $\mathrm{CaCO}_{3}$ production per unit area remained relatively constant $\left(\sim 7 \mathrm{~kg} \mathrm{CaCO}_{3} \mathrm{~m}^{-2}\right.$ year $^{-1}$; Figure 4 and Table S1) across 10 years of study period, despite fluctuations in coral cover (Figure 2). In contrast, the allometric model revealed marked variation in reef-scale $\mathrm{CaCO}_{3}$ production over the same period. $\mathrm{CaCO}_{3}$ production per unit area increased from $9 \mathrm{~kg} \mathrm{CaCO}_{3} \mathrm{~m}^{-2}$ year $^{-1}$ during pre-disturbance in 2005 to $17 \mathrm{~kg} \mathrm{CaCO}_{3} \mathrm{~m}^{-2}$ year $^{-1}$ in 2010 and $22 \mathrm{~kg} \mathrm{CaCO}_{3} \mathrm{~m}^{-2}$ year $^{-1}$ in 2013 during reef recovery (Figure $4 a$ and Table S1). These peaks co-occurred with the recolonization of juvenile corals (Adjeroud et al., 2018), initiated in 2006 in response to the Acanthaster outbreak, but it was interrupted by the cyclone in 2010 (Kayal et al., 2012). After 2013, coral colonies grew steadily, leading to a gradual decline in the production of $\mathrm{CaCO}_{3}$ per unit area. Overall, the isometric model led to a $40 \%$ underestimation of the total $\mathrm{CaCO}_{3}$ produced over 10 years compared to our allometric model (Figure 4b).

To test how reduced coral recruitment impacts reef-scale $\mathrm{CaCO}_{3}$ production, we simulated coral community composition and size structure across 5 years of recovery period under four different scenarios of decline in coral recruitment $(0 \%, 25 \%, 50 \%$, and $75 \%$ declines). Recruitment declines dramatically reduced $\mathrm{CaCO}_{3}$ production, with a $68 \%$ reduction in $\mathrm{CaCO}_{3}$ production when recruitment is reduced by $75 \%$ (Figure 5). Even a moderate decline of $25 \%$ in recruitment reduced post-disturbance $\mathrm{CaCO}_{3}$ production by $\sim 30 \%$ over 5 years.

\section{4 | DISCUSSION}

Our study demonstrates that three major reef-building corals in Mo'orea (Acropora hyacinthus, Pocillopora verrucosa, and Porites lutea) 


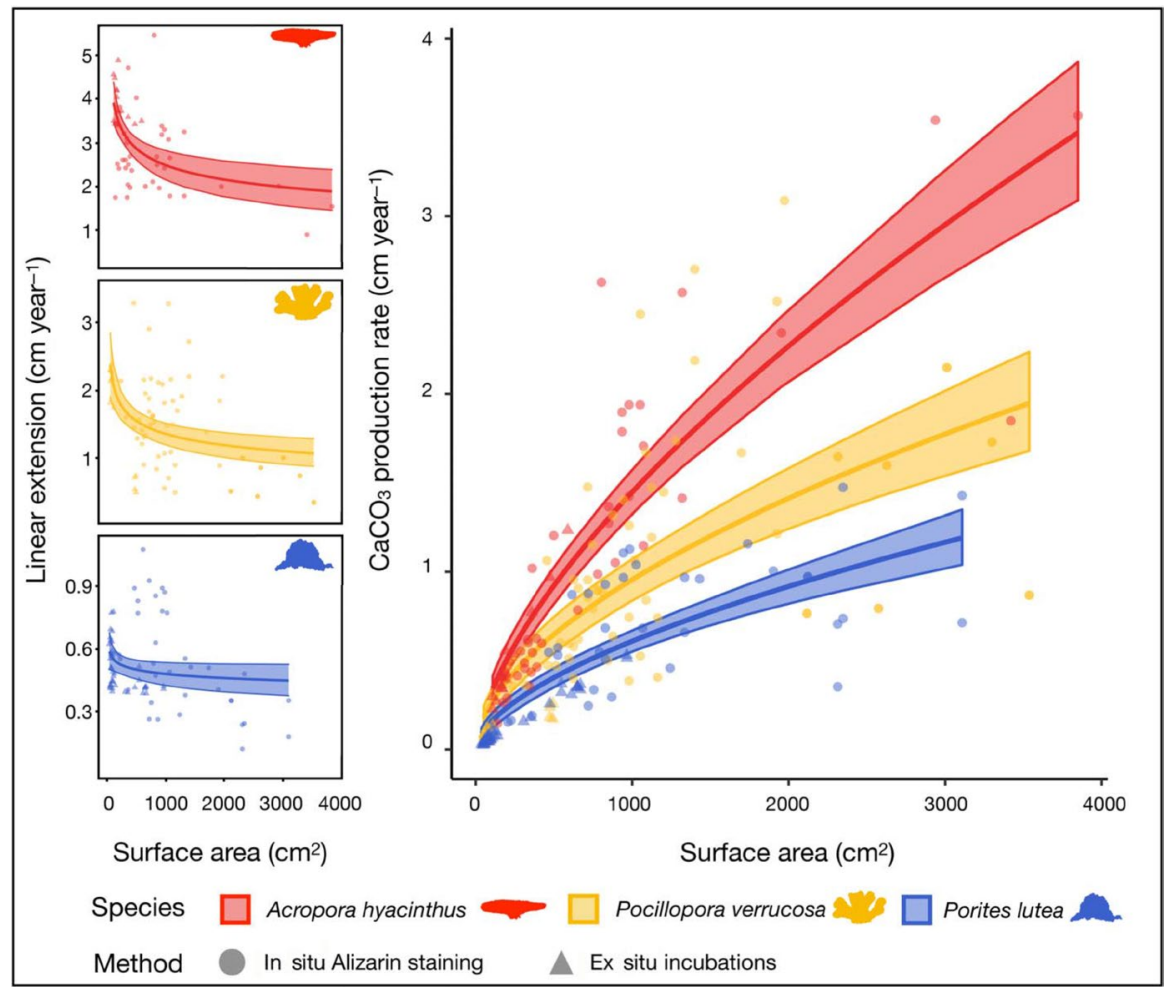

FIGURE $3 \mathrm{CaCO}_{3}$ production rates of the three reef-building coral species. On the left, changes in linear extension for the coral species $A$. hyacinthus, $P$. verrucosa, and $P$. lutea as a function of colony size. On the right, changes in $\mathrm{CaCO}_{3}$ production rates as a function of colony size. $\mathrm{CaCO}_{3}$ production was estimated using two growth measurement methods (in situ alizarin red-S staining and ex situ metabolic incubations) [Colour figure can be viewed at wileyonlinelibrary. com] show allometric linear extension and $\mathrm{CaCO}_{3}$ production patterns. Using the allometric patterns to quantify reef-scale $\mathrm{CaCO}_{3}$ production from coral size structure time series in Mo'orea indicates that the conventional isometric approach leads to a $40 \%$ underestimation of $\mathrm{CaCO}_{3}$ production over 10 years. Our results imply that recovering reefs have exceptionally high calcification rates due to the fast growth of juvenile corals. Thus, static metrics of coral community assemblages (e.g., percentage of live coral cover, may mask dynamic processes that underpin the functioning of reefs (Brandl, Tornabene, et al., 2019; Morais \& Bellwood, 2019).

Over a 10-year-period in Mo'orea, assumption of isometry resulted in an average underestimation of $3 \mathrm{~kg} \mathrm{~m}^{-2}$ year $^{-1}$, which equals approximately half of the bioerosion caused by sea urchins and parrot fishes around Mo'orea per year (i.e., $~ 6 \mathrm{~kg} \mathrm{~m}^{-2}$ year $^{-1}$; Alvarado et al., 2016; Peyrot-Clausade et al., 2000). Although allometric growth, when expressed as an increase in planar area, has been documented for corals (Dornelas et al., 2017), this pattern most likely arose from the higher probability of partial mortality in larger colonies, and thus lower increases in planar area (Kayal et al., 2015; Madin et al., 2020; Pratchett et al., 2015), rather than inherent differences in growth rate across ontogeny. Our ex situ estimates of $\mathrm{CaCO}_{3}$ production were not sensitive to the potential effects of partial mortality for two reasons. First, they are nearly instantaneous measures (Gattuso et al., 1998) on small colonies in which partial mortality is less prevalent. Second, partial mortality is often due to predation or overgrowth, which is easily excluded in controlled ex situ experiments. Although alizarin red-S staining was conducted in the field, where partial mortality can be observed, we carefully selected healthy branches that did not show signs of predation or overgrowth.
Thus, allometric growth likely results from shifts in the energy allocated to $\mathrm{CaCO}_{3}$ production across the colony size gradient. Indeed, larger colonies may invest substantial energy in reproduction, which might reduce the energy available for calcification (Kayal et al., 2015).

Our findings also have important implications for our understanding of system-wide reef accretion rates under climate change. Indeed, reef accretion depends on the net community production of $\mathrm{CaCO}_{3}$ (Perry et al., 2012) and our results suggest that, after a perturbation, small colonies may greatly bolster community-level $\mathrm{CaCO}_{3}$ production (see also Gilmour et al., 2013). However, the presence of juvenile corals strongly depends on the reproductive capacity of mature coral colonies (Edmunds, 2017; Holbrook et al., 2018; Vercelloni et al., 2019). Severe, large-scale, and repeated disturbances can dramatically erode the supply of coral recruits to large swaths of reefs. For example, coral recruitment on the Australian Great Barrier Reef in 2018 declined by $89 \%$ in response to the loss of corals during 2016 and 2017 bleaching events (Hughes et al., 2019). Our results indicate that disruption and decline of coral recruitment may lead to a decrease in the production of $\mathrm{CaCO}_{3}$ with a potentially profound impact on reef accretion. In fact, because juvenile corals play a disproportionate role in $\mathrm{CaCO}_{3}$ production, reductions in coral recruitment following disturbances, such as extensive coral bleaching, may undermine the capacity of reef ecosystems to recover and, ultimately, endanger the persistence of reefs that protect tropical coasts (Oppenheimer et al., 2019).

Area-normalized $\mathrm{CaCO}_{3}$ production showed a nearly inverted profile (Figure 4a) compared to coral cover, emphasizing the deep divide between metrics of ecosystem function (e.g., growth, $\mathrm{CaCO}_{3}$ 


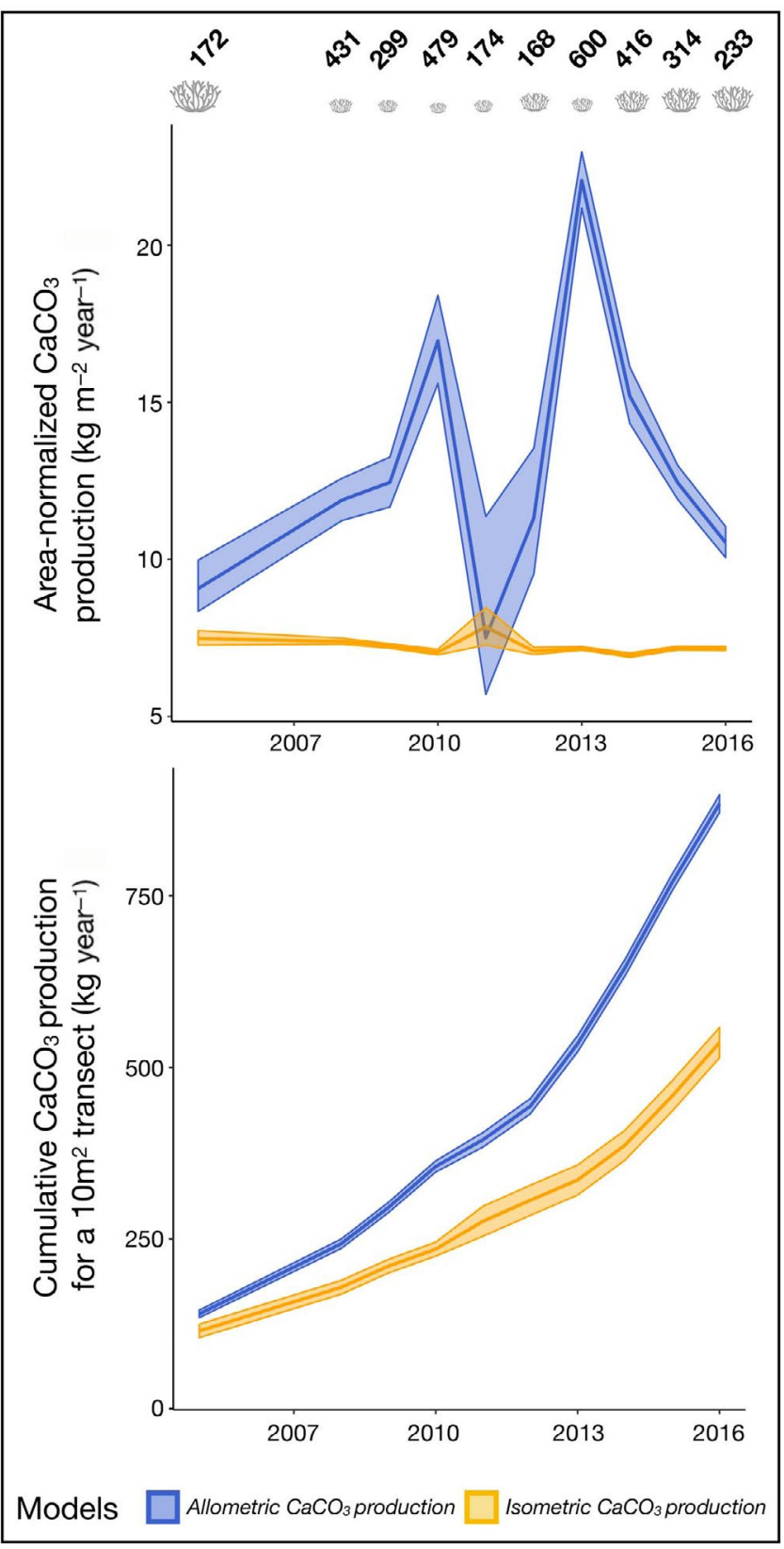

FIGURE 4 Coral community $\mathrm{CaCO}_{3}$ production estimates of a $10 \mathrm{~m}^{2}$ portion of reef substrate in Mo'orea from 2005 to 2016 according to the isometric versus allometric coral $\mathrm{CaCO}_{3}$ production models. (a) $\mathrm{CaCO}_{3}$ production rate $\left(\mathrm{kg} \mathrm{m}^{-2}\right.$ year $\left.^{-1}\right)$, (b) cumulative $\mathrm{CaCO}_{3}$ production (kg/year). Estimates are bounded by a 95\% confidence interval. Coral symbols on top indicate changes in average coral colony size, and numbers indicate coral colony density per $10 \mathrm{~m}^{2}$ of reef surface area [Colour figure can be viewed at wileyonlinelibrary.com]

production) and their outcomes (e.g., coral cover, structural complexity). As a consequence, much of coral reef monitoring is likely to evaluate outcomes of past reef configurations rather than current levels of functioning. To efficiently monitor and protect coral reefs in times of unprecedented anthropogenic and climatic impacts, our results emphasize the need to move beyond ecosystem assessments based solely on static surveys (e.g., coral cover or fish biomass) and consider metrics that quantify reef functioning as a dynamic process

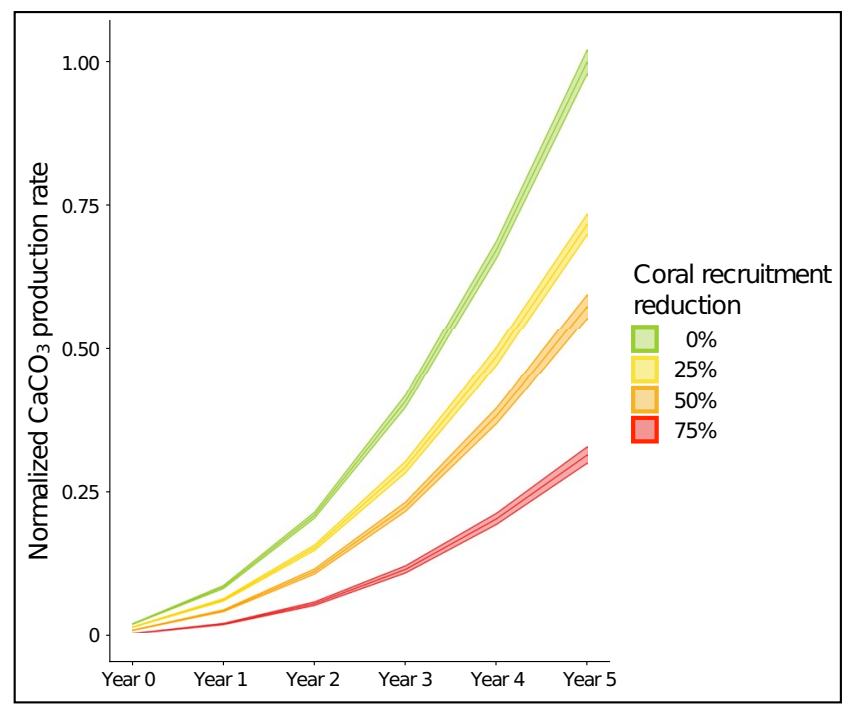

FIGURE 5 Normalized $\mathrm{CaCO}_{3}$ production trajectories according to four scenarios of coral recruitment over 5 years during reef recovery. A multispecies, open-population integral projection model was used to predict the recovery dynamics of an assemblage of three coral genera (Acropora, Pocillopora, and Porites) based on coral demographic performance (in recruitment, growth, and survival) measured in Mo'orea. The four scenarios predicted different rates of coral recruitment reduction as compared to current levels (0\%, 25\%,50\%, and $75 \%$ reductions). $\mathrm{CaCO}_{3}$ production rates were estimated from model predictions of coral abundance, composition, and size distribution (Figure S5, combined with the allometric $\mathrm{CaCO}_{3}$ production functions estimated in Mo'orea; Figure 1). $\mathrm{CaCO}_{3}$ production rates were normalized relative to the highest value (scenario $0 \%$ reduction at year 5 ; green curve [Colour figure can be viewed at wileyonlinelibrary.com]

(Brandl, Rasher, et al., 2019; Darling et al., 2012; Edmunds \& Riegl, 2020; Madin et al., 2016).

Overall, we provide a novel perspective on coral reef $\mathrm{CaCO}_{3}$ production that has direct implications for the security of coastal populations throughout the tropics (Arkema et al., 2013; Perry, Alvarez-Filip, et al., 2018). With current projections of global change, reefs will face disturbances such as coral bleaching at increasing frequencies. After these disturbances, juvenile corals can buffer the decrease in community $\mathrm{CaCO}_{3}$ production caused by live coral loss through their rapid growth. However, reductions in coral recruitment, as recorded after large-scale disturbances, will undermine this buffering capacity, ultimately hampering vertical reef accretion and consequently the protection of tropical coasts from oceanic waves. The buffering capacity of small colonies provides only a short-term boost (until colonies grow bigger) that may support a faster return to pre-disturbance levels of coral cover and reef structural complexity. Yet, vertical reef accretion happens over a much longer time frame and relies on several other factors such as substrate cementation by coralline algae and sediment input (Perry et al., 2012; Perry, Lange, et al., 2018). Thus, despite the capacity of juvenile corals to temporarily accelerate reef recovery through rapid growth, long-term persistence of coral reefs and their services inevitably hinge on the preservation of coral populations across size classes. 


\section{ACKNOWLEDGEMENTS}

We thank the "Service d'Observatoire CORAIL" (SO CORAIL) and the Mo'orea Coral Reef Long Term Ecological Research (LTER) programs. We also thank Yann Lacube and Adeline Goyaud for help with alizarin red-S staining, Martin Alessandrini and Hmeniko Tourancheau for help defining linear coral extension rates, technical support from the Université de Perpignan and the Banyuls sur Mer Observatory (Fabien Morat, Guillaume Iwankow, Titouan Morage, and David Pecqueur), and Joshua Madin for reviewing our manuscript before submission.

\section{CONFLICTS OF INTEREST}

None declared.

\section{AUTHOR CONTRIBUTIONS}

J.C and V.P conceived the idea and methods. J.C performed the alizarin red-S staining, and J.C, A.M, B.E, and U.C performed the incubation experiments. M.A, H.S.L., and M.K performed the size distribution surveys. J.C. performed the photogrammetry. J.C. created the growth model and M.K. built the recruitment scenarios model. J.C wrote the first draft of the paper, and all co-authors contributed to revisions and approved the final draft.

\section{DATA AVAILABILITY STATEMENT}

Code and data are available on https://github.com/JayCrlt/Allom etric_coral_growth.git

\section{ORCID}

Jérémy Carlot (iD https://orcid.org/0000-0003-0887-8005

Mohsen Kayal (D) https://orcid.org/0000-0003-3675-9855

Hunter S. Lenihan (D) https://orcid.org/0000-0001-8146-7670

Simon J. Brandl (D) https://orcid.org/0000-0002-6649-2496

Jordan M. Casey (D) https://orcid.org/0000-0002-2434-7207

Mehdi Adjeroud (D) https://orcid.org/0000-0002-6825-8759

Ulisse Cardini (D) https://orcid.org/0000-0002-0816-6158

Diego R. Barneche (D) https://orcid.org/0000-0002-4568-2362

Alessio Rovere (D) https://orcid.org/0000-0001-5575-1168

Valeriano Parravicini (D) https://orcid.org/0000-0002-3408-1625

\section{REFERENCES}

Adjeroud, M., Kayal, M., Iborra-Cantonnet, C., Vercelloni, J., Bosserelle, P., Liao, V., Chancerelle, Y., Claudet, J., \& Penin, L. (2018). Recovery of coral assemblages despite acute and recurrent disturbances on a South Central Pacific reef. Scientific Reports, 8(1), 9680. https://doi. org/10.1038/s41598-018-27891-3

Adjeroud, M., Mauguit, Q., \& Penin, L. (2015). The size-structure of corals with contrasting life-histories: A multi-scale analysis across environmental conditions. Marine Environmental Research, 112, 131139. https://doi.org/10.1016/j.marenvres.2015.10.004

Agisoft LLC. (2016). Agisoft PhotoScan user manual: Professional edition, version 1.2. User Manuals (p. 97). Retrieved from http://www. agisoft.com/downloads/user-manuals/

Alvarado, J. J., Cortés, J., Guzman, H., \& Reyes-Bonilla, H. (2016). Bioerosion by the sea urchin Diadema mexicanum along Eastern Tropical Pacific coral reefs. Marine Ecology, 37(5), 1088-1102. https://doi.org/10.1111/maec.12372
Arkema, K. K., Guannel, G., Verutes, G., Wood, S. A., Guerry, A., Ruckelshaus, M., Kareiva, P., Lacayo, M., \& Silver, J. M. (2013). Coastal habitats shield people and property from sea-level rise and storms. Nature Climate Change, 3(10), 913-918. https://doi. org/10.1038/nclimate1944

Brandl, S., Rasher, D. B., Côté, I. M., Casey, J. M., Darling, E. S., Lefcheck, J. S., \& Duffy, J. E. (2019). Coral reef ecosystem functioning: Eight core processes and the role of biodiversity. Frontiers in Ecology and the Environment, 17(8), 445-454. https://doi.org/10.1002/ fee. 2088

Brandl, S. J., Tornabene, L., Goatley, C. H. R., Casey, J. M., Morais, R. A., Côté, I. M., Baldwin, C. C., Parravicini, V., Schiettekatte, N. M. D., \& Bellwood, D. R. (2019). Demographic dynamics of the smallest marine vertebrates fuel coral reef ecosystem functioning. Science, 364(6446), 1189-1192. https://doi.org/10.1126/ science.aav3384

Bürkner, P.-C. (2017a). Advanced Bayesian multilevel modeling with the R package brms. The R Journal, 10(1), 395. https://doi.org/10.32614/ RJ-2018-017

Bürkner, P.-C. (2017b). brms: An R package for Bayesian multilevel models using stan. Journal of Statistical Software, 1(1). https://doi. org/10.18637/jss.v080.i01

Carlot, J., Rovère, A., Casella, E., Harris, D., Grellet-Muñoz, C., Chancerelle, Y., Dormy, E., Hedouin, L., \& Parravicini, V. (2020). Community composition predicts photogrammetry-based structural complexity on coral reefs. Coral Reefs, 39(4), 967-975. https:// doi.org/10.1007/s00338-020-01916-8

Darling, E. S., Alvarez-Filip, L., Oliver, T. A., McClanahan, T. R., \& Côté, I. M. (2012). Evaluating life-history strategies of reef corals from species traits. Ecology Letters, 15(12), 1378-1386. https://doi. org/10.1111/j.1461-0248.2012.01861.x

Darling, E. S., McClanahan, T. R., Maina, J., Gurney, G. G., Graham, N. A. J., Januchowski-Hartley, F., Cinner, J. E., Mora, C., Hicks, C. C., Maire, E., Puotinen, M., Skirving, W. J., Adjeroud, M., Ahmadia, G., Arthur, R., Bauman, A. G., Beger, M., Berumen, M. L., Bigot, L., ... Mouillot, D. (2019). Social-environmental drivers inform strategic management of coral reefs in the Anthropocene. Nature Ecology \& Evolution, 3(9), 1341-1350. https://doi.org/10.1038/s41559-019-0953-8

Dickson, A. G., Sabine, C. L., \& Christian, J. R. (2007). Guide to best practices for ocean $\mathrm{CO}_{2}$ measurements. North Pacific Marine Science Organization.

Dietzel, A., Bode, M., Connolly, S. R., \& Hughes, T. P. (2020). Longterm shifts in the colony size structure of coral populations along the Great Barrier Reef. Proceedings of the Royal Society B: Biological Sciences, 287(1936), 20201432. https://doi.org/10.1098/ rspb.2020.1432

Dornelas, M., Madin, J. S., Baird, A. H., \& Connolly, S. R. (2017). Allometric growth in reef-building corals. Proceedings of the Royal Society B: Biological Sciences, 284(1851), 20170053. https://doi.org/10.1098/ rspb.2017.0053

Dustan, P. (1975). Growth and form in the reef-building coral Montastrea annularis. Marine Biology, 33(2), 101-107.

Edmunds, P. J. (2017). Unusually high coral recruitment during the 2016 El Niño in Mo'orea, French Polynesia. PLoS One, 12(10), e0185167. https://doi.org/10.1371/journal.pone.0185167

Edmunds, P. J., \& Riegl, B. (2020). Urgent need for coral demography in a world where corals are disappearing. Marine Ecology Progress Series, 635, 233-242.

Ellison, J. C., Han, P., \& Lewis, T. W. (2019). Carbonate beach sand of Abaiang Atoll, Kiribati: Geochemistry, biogenic sources, and properties. Atoll Research Bulletin, 621, 1-21.

Gattuso, J.-P., Frankignoulle, M., Bourge, I., Romaine, S., \& Buddemeier, R. W. (1998). Effect of calcium carbonate saturation of seawater on coral calcification. Global and Planetary Change, 18(1), 37-46. https://doi.org/10.1016/S0921-8181(98)00035-6 
Gilmour, J. P., Smith, L. D., Heyward, A. J., Baird, A. H., \& Pratchett, M. S. (2013). Recovery of an isolated coral reef system following severe disturbance. Science, 340(6128), 69-71. https://doi.org/10.1126/ science. 1232310

Harris, D. L., Rovere, A., Casella, E., Power, H., Canavesio, R., Collin, A., Pomeroy, A., Webster, J. M., \& Parravicini, V. (2018). Coral reef structural complexity provides important coastal protection from waves under rising sea levels. Science Advances, 4(2), eaao4350. https://doi.org/10.1126/sciadv.aao4350

Hoegh-Guldberg, O., Mumby, P. J., Hooten, A. J., Steneck, R. S., Greenfield, P., Gomez, E., Harvell, C. D., Sale, P. F., Edwards, A. J., Caldeira, K., Knowlton, N., Eakin, C. M., Iglesias-Prieto, R., Muthiga, N., Bradbury, R. H., Dubi, A., \& Hatziolos, M. E. (2007). Coral reefs under rapid climate change and ocean acidification. Science, 318(5857), 1737-1742. https://doi.org/10.1126/scien ce. 1152509

Holbrook, S. J., Adam, T. C., Edmunds, P. J., Schmitt, R. J., Carpenter, R. C., Brooks, A. J., Lenihan, H. S., \& Briggs, C. J. (2018). Recruitment drives spatial variation in recovery rates of resilient coral reefs. Scientific Reports, 8(1), 7338. https://doi.org/10.1038/s41598-01825414-8

Hughes, T. P., Kerry, J. T., Álvarez-Noriega, M., Álvarez-Romero, J. G., Anderson, K. D., Baird, A. H., Babcock, R. C., Beger, M., Bellwood, D. R., Berkelmans, R., Bridge, T. C., Butler, I. R., Byrne, M., Cantin, N. E., Comeau, S., Connolly, S. R., Cumming, G. S., Dalton, S. J., DiazPulido, G., ... Wilson, S. K. (2017). Global warming and recurrent mass bleaching of corals. Nature, 543(7645), 373-377. https://doi. org/10.1038/nature21707

Hughes, T. P., Kerry, J. T., Baird, A. H., Connolly, S. R., Chase, T. J., Dietzel, A., Hill, T., Hoey, A. S., Hoogenboom, M. O., Jacobson, M., Kerswell, A., Madin, J. S., Mieog, A., Paley, A. S., Pratchett, M. S., Torda, G., \& Woods, R. M. (2019). Global warming impairs stock-recruitment dynamics of corals. Nature, 568(7752), 387-390. https://doi. org/10.1038/s41586-019-1081-y

Hughes, T. P., \& Tanner, J. E. (2000). Recruitment failure, life histories, and long-term decline of caribbean corals. Ecology, 81(8), 22502263. https://doi.org/10.1890/0012-9658(2000)081[2250:RFLHA L]2.0.CO;2

Kayal, M., Lenihan, H. S., Brooks, A. J., Holbrook, S. J., Schmitt, R. J., \& Kendall, B. E. (2018). Predicting coral community recovery using multi-species population dynamics models. Ecology Letters, 21(12), 1790-1799. https://doi.org/10.1111/ele.13153

Kayal, M., Vercelloni, J., Lison de Loma, T., Bosserelle, P., Chancerelle, Y., Geoffroy, S., Stievenart, C., Michonneau, F., Penin, L., Planes, S., \& Adjeroud, M. (2012). Predator crown-of-thorns starfish (Acanthaster planci) outbreak, mass mortality of corals, and cascading effects on reef fish and benthic communities. PLoS One, 7(10), e47363. https://doi.org/10.1371/journal.pone.0047363

Kayal, M., Vercelloni, J., Wand, M. P., \& Adjeroud, M. (2015). Searching for the best bet in life-strategy: A quantitative approach to individual performance and population dynamics in reef-building corals. Ecological Complexity, 23, 73-84. https://doi.org/10.1016/j. ecocom.2015.07.003

Kolb, R. W. (2018). National ambient air quality standards (NAAQS). In The SAGE encyclopedia of business ethics and society. SAGE Publications, Inc. https://doi.org/10.4135/9781483381503.n817

Madin, J. S., Anderson, K. D., Andreasen, M. H., Bridge, T. C. L., Cairns, S. D., Connolly, S. R., Darling, E. S., Diaz, M., Falster, D. S., Franklin, E. C., Gates, R. D., Harmer, A. M. T., Hoogenboom, M. O., Huang, D., Keith, S. A., Kosnik, M. A., Kuo, C.-Y., Lough, J. M., Lovelock, C. E., ... Baird, A. H. (2016). The Coral Trait Database, a curated database of trait information for coral species from the global oceans. Scientific Data, 3(1), 160017. https://doi.org/10.1038/sdata.2016.17

Madin, J. S., Baird, A. H., Baskett, M. L., Connolly, S. R., \& Dornelas, M. A. (2020). Partitioning colony size variation into growth and partial mortality. Biology Letters, 16(1), 20190727. https://doi.org/10.1098/ rsbl.2019.0727

Morais, R. A., \& Bellwood, D. R. (2019). Pelagic subsidies underpin fish productivity on a degraded coral reef. Current Biology, 29(9), 15211527.e6. https://doi.org/10.1016/j.cub.2019.03.044

Morgan, K. M., \& Kench, P. S. (2012). Skeletal extension and calcification of reef-building corals in the central Indian Ocean. Marine Environmental Research, 81, 78-82. https://doi.org/10.1016/j.marenvres.2012. 08.001

Nunn, P., Kohler, A., \& Kumar, R. (2017). Identifying and assessing evidence for recent shoreline change attributable to uncommonly rapid sea-level rise in Pohnpei, Federated States of Micronesia, Northwest Pacific Ocean. Journal of Coastal Conservation, 21(6), 719-730. https://doi.org/10.1007/s11852-017-0531-7

Oppenheimer, M., Glavovic, B., Hinkel, J., van de Wal, R., Magnan, A. K., Abd-Elgawad, A., Cai, R., Cifuentes-Jara, M., DeConto, R. M., Ghosh, T., Hay, J., Isla, F., Marzeion, B., Meyssignac, B., \& Sebesvari, Z. (2019). Sea Level Rise and Implications for Low Lying Islands, Coasts and Communities. IPCC Special Report on the Ocean and Cryosphere in a Changing Climate, 355(6321), 126-129.

Perry, C. T., Alvarez-Filip, L., Graham, N. A. J., Mumby, P. J., Wilson, S. K., Kench, P. S., Manzello, D. P., Morgan, K. M., Slangen, A. B. A., Thomson, D. P., Januchowski-Hartley, F., Smithers, S. G., Steneck, R. S., Carlton, R., Edinger, E. N., Enochs, I. C., Estrada-Saldívar, N., Haywood, M. D. E., Kolodziej, G., ... Macdonald, C. (2018). Loss of coral reef growth capacity to track future increases in sea level. Nature, 558(7710), 396-400. https://doi.org/10.1038/s4158 6-018-0194-z

Perry, C. T., Edinger, E. N., Kench, P. S., Murphy, G. N., Smithers, S. G., Steneck, R. S., \& Mumby, P. J. (2012). Estimating rates of biologically driven coral reef framework production and erosion: A new censusbased carbonate budget methodology and applications to the reefs of Bonaire. Coral Reefs, 31(3), 853-868. https://doi.org/10.1007/ s00338-012-0901-4

Perry, C. T., Lange, I., \& Januchowski-Hartley, F. A. (2018). ReefBudget Indo-Pacific: Online resource and methodology. Retrieved from http://geography.exeter.ac.uk/reefbudget/

Peyrot-Clausade, M., Chabanet, P., Conand, C., Fontaine, M. F., Letourneur, Y., \& Harmelin-Vivien, M. (2000). Sea urchin and fish bioerosion on La Réunion and Moorea reefs. Bulletin of Marine Science, 66(2), 477-485.

Pinheiro, J., Bates, D., DebRoy, S., \& Sarkar, D.; R Core Team. (2013). nlme: Linear and nonlinear mixed effects models. R Package Version, 3(1), 111.

Pratchett, M. S., Anderson, K. D., Hoogenboom, M. O., Widman, E., Baird, A. H., Pandolfi, J. M., Edmunds, P. J., \& Lough, J. M. (2015). Spatial, temporal and taxonomic variation in coral growth-implications for the structure and function of coral reef ecosystems. Oceanography and marine biology: An annual review (Vol. 53, pp. 215-295). CRC Press. https://doi.org/10.1201/b18733

R Core Team. (2019). R: A language and environment for statistical computing. R Foundation for Statistical Computing.

Schneider, C. A., Rasband, W. S., \& Eliceiri, K. W. (2012). NIH Image to ImageJ: 25 years of image analysis. Nature Methods, 9(7), 671-675. https://doi.org/10.1038/nmeth.2089

Smith, L. W., Barshis, D., \& Birkeland, C. (2007). Phenotypic plasticity for skeletal growth, density and calcification of Porites lobata in response to habitat type. Coral Reefs, 26(3), 559-567. https://doi. org/10.1007/s00338-007-0216-z

Smith, S. V., \& Key, G. S. (1975). Carbon dioxide and metabolism in marine environments. Limnology and Oceanography, 20(3), 493-495.

Tebaldi, C., Strauss, B. H., \& Zervas, C. E. (2012). Modelling sea level rise impacts on storm surges along US coasts. Environmental Research Letters, 7(1), 14032. https://doi.org/10.1088/174 8-9326/7/1/014032 
van Hooidonk, R., Maynard, J., Tamelander, J., Gove, J., Ahmadia, G. Raymundo, L., Williams, G., Heron, S. F., \& Planes, S. (2016). Localscale projections of coral reef futures and implications of the Paris Agreement. Scientific Reports, 6(1), 39666. https://doi.org/10.1038/ srep39666

Vercelloni, J., Kayal, M., Chancerelle, Y., \& Planes, S. (2019). Exposure, vulnerability, and resiliency of French Polynesian coral reefs to environmental disturbances. Scientific Reports, 9(1), 1027. https://doi. org/10.1038/s41598-018-38228-5

Woodroffe, C. D., \& Webster, J. M. (2014). Coral reefs and sea-level change. Marine Geology, 352, 248-267. https://doi.org/10.1016/j. margeo.2013.12.006

\section{SUPPORTING INFORMATION}

Additional supporting information may be found online in the Supporting Information section.

How to cite this article: Carlot J, Kayal M, Lenihan HS, et al. Juvenile corals underpin coral reef carbonate production after disturbance. Glob Change Biol. 2021;27:2623-2632. https://doi. org/10.1111/gcb.15610 